\title{
VARIANCE ASSOCIATED WITH CLONING *
}

\author{
W. J. LIBBY and E. JUND \\ Department of Genetics, University of California, Berkeley, California $\dagger$
}

\section{INTRODUCTION}

Received 3.iii.62

WITHIN the last decade, several workers have utilised clones in estimating variance components (Burton and DeVane, 1953; Keller and Likens, I955; Comstock, Kelleher and Morrow, I958; Toda, I 958; Cooper, I959; Libby, I962) and in selection (Burton and DeVane, I953; Keller and Likens, I955; Morrow, Comstock and Kelleher, I 958). One objection to such use concerns the possibility of variation associated with cloning, which may bias one or more of the component estimates, or reduce the efficiency of selection.

Consider a population of non-identical genotypes growing in a non-uniform environment. Each plant has developed a physiology and morphology in response to its unique genotype and its unique micro-environment. Now clone each plant (termed an ortet) by placing vegetative propagules (termed ramets) at random in a nonuniform environment. After a suitable period of growth, the resulting ramets are scored for some character, and are found to vary within a clone. This is due to local differences between their new microenvironments, and possibly to inequalities between the propagules at cloning, a type of variance associated with cloning. However, on the average, ramets within a clone are more similar to each other than to ramets from the other clones. They are more similar because they are the same genotype, and possibly also because the vegetative parts had similar if not identical physiological and morphological characteristics at the time of cloning, which were the product of a unique genotype-environment collaboration in the ortet. It is this last situation which leads to " $c$ " effects variation in a population of clones, and non-genetic covariation within clones, which is of interest in this paper.

Donald (1958) has reported an experiment with twin cattle, in which the proportion of variation in live weight ascribable to maternal effects was measured at two weeks, three months, and 18 months of age. He found that maternal effects decreased from 50 per cent. of the variation at two weeks, to $3^{8}$ per cent. at three months, to only 5 per cent. at 18 months. Similar results have been obtained from four experiments with yellow monkey flower (Mimulus guttatus Fisch.).

* Part of a dissertation submitted to the Graduate Division, University of California, by the senior author in partial fulfilment of the requirements for the degree of Doctor of Philosophy in Genetics.

$\dagger$ Now at School of Forestry, University of California, Berkeley, and retired, respectively. 


\section{MATERIALS AND METHODS}

The basic design and concept of all four experiments was the same : to utilise differences in the physiological and morphological condition of genetically identical plants to test whether differences related to the source of ramets within clones could be detected. The same five clones were used in all four experiments (cultural details are given in Libby, 1962). They were chosen from a larger population sample on the basis of leaf shape and calyx markings, which distinguished each from the other four.

The first two experiments tested the effect of age of the ortet. In the first experiment, plants which had grown for three, seven and eleven weeks, after themselves originating as rooted nodes, were used as ortets within each clone. Three comparable rooted nodes from runners were taken from each $(\mathcal{N}=45: 3$ ramets/age for each of 5 clones), potted, and randomly positioned in shallow trays of water in the greenhouse in June, 1960. Plants four, eight and twelve weeks from cloning were used as ortets in the second experiment, with four ramets similarly taken from each $(\mathcal{N}=60)$ in October, 1960.

In the third experiment, only one plant per clone was used as an ortet. The five ortets were all in the same stage of development, having themselves originated from young rooted nodes ten weeks earlier. Four young axillary branches were cut from each plant and rooted in moist sand. They developed adequate roots in one week, and were randomly positioned along with four rooted nodes per ortet from runners which had developed on the surface of the soil, and four rooted nodes per ortet from runners which had developed under water $(\mathcal{N}=60)$ (see plate, top).

In the fourth experiment, one ramet of each clone was grown in a pot placed in water in the greenhouse, a second in a pot placed in sand in the greenhouse, a third in a pot placed in water on an outside bench, and a fourth in a pot placed in sand on an outside bench. They were grown in these four environments from July to mid-September, 1960, then recloned into fresh pots, which were kept in their respective environments for another month. During this final month, the major features of the four environments were : (I) Warm nights, long days ( 16 hours), and saturated soil ; (2) Warm nights, long days, and repeated water stress ; (3) Variable and occasionally cold nights, decreasing day length (I 3 to I I hours), and saturated soil ; and (4) Variable and occasionally cold nights, decreasing day length, and repeated water stress. On $15^{\text {th }}$ October, these plants (now ortets) were each the source of four rooted nodes from runners, which were randomly positioned in the trays of water in the greenhouse $(\mathcal{N}=80)$ (see plate, bottom).

In all four experiments, the ramets were scored for total height at four weeks, days to produce the first flower, height to the first flowering node, and length of the six internodes immediately above the first flowering node. These four characters would be expected to be controlled by many of the same physiological and genetic systems. The first three, in fact, all show strong correlated response to selection for the fourth, six-internode length (Libby, 1961).

Variance components were estimated for treatments (age of ortets, type of rooted node, or ortet environment), clones, treatment $\times$ clone interaction, and environment of the ramets, according to the fixed-effects model analysis of variance (Scheffe, 1959, chap. 4.3). The treatment and interaction components reflect the influence of the physiological and morphological differences in the source of the ramets within clones, while the clonal and interaction components reflect the importance of the different genotypes in determining the characters. The ramet environment component reflects primarily the effect of the experiment microenvironments on expression of the characters.

\section{RESULTS}

As an example, table I presents the grouped data, means of the treatments, clones, and treatment $\times$ clone combinations, and the 
summary of the analysis for one character in one experiment. In this example, it appears that ramets from ortets grown outside tend to flower earlier than those from ortets grown in the greenhouse (possibly

TABLE I

Number of days from planting until first flower

\begin{tabular}{|c|c|c|c|c|c|c|c|}
\hline \multirow{2}{*}{\multicolumn{2}{|c|}{$\begin{array}{l}\text { Parent (Ortet) } \\
\text { Environment }\end{array}$}} & \multicolumn{5}{|c|}{ Clone number } & \multirow{2}{*}{ Mean } \\
\hline & & 217 & I 34 & I 38 & 338 & 222 & \\
\hline Inside water & - & $\begin{array}{cc}5^{8} & 4^{8} \\
58 & 64 \\
57 \cdot 0\end{array}$ & $\begin{array}{cc}54 & 65 \\
57 & 5^{6} \\
58 \cdot 0^{6}\end{array}$ & $\begin{array}{cc}78 & 57 \\
63 & 70 \\
67 \cdot 0\end{array}$ & $\begin{array}{cr}67 & 58 \\
59 & 65 \\
62 \cdot 2\end{array}$ & $\begin{array}{cc}65 & 52 \\
53 & 65 \\
58 \cdot 8\end{array}$ & $60 \cdot 6$ \\
\hline Inside sand & & $\begin{array}{cc}63 & 52 \\
61 & 74 \\
62.5\end{array}$ & $\begin{array}{cc}42 & 54 \\
58 & 57 \\
52 \cdot 8\end{array}$ & $\begin{array}{cc}64 & 57 \\
62 & 62 \\
6 r \cdot 2\end{array}$ & $\begin{array}{cr}59 & 56 \\
73 & 67 \\
63 \cdot 8\end{array}$ & $\begin{array}{cc}62 & 58 \\
81 & 60 \\
65 \cdot 2\end{array}$ & $6 \mathrm{I} \cdot 1$ \\
\hline Outside water & . & $\begin{array}{cc}63 & 63 \\
59 & 63 \\
62 \cdot 0\end{array}$ & $\begin{array}{cc}43 & 6 \mathrm{I} \\
5^{8} & 5^{\mathrm{O}} \\
53^{\circ} & \end{array}$ & $\begin{array}{cc}51 & 49 \\
54 & 53 \\
5^{I} \cdot 8\end{array}$ & $\begin{array}{cc}54 & 54 \\
5^{8} & 60 \\
5^{6} \cdot 5\end{array}$ & $\begin{array}{cc}52 & 54 \\
45 & 5^{1} \\
50 \cdot 5\end{array}$ & $54^{\cdot 8}$ \\
\hline Outside sand & & $\begin{array}{cc}5 \mathrm{I} & 54 \\
60 & 80 \\
6 I \cdot 2\end{array}$ & $\begin{array}{cc}59 & 45 \\
52 & 4^{8} \\
5^{I} \cdot 0^{\circ}\end{array}$ & $\begin{array}{cc}65 \quad 60 \\
74 & 60 \\
64 & 8\end{array}$ & $\begin{array}{cc}59 & 5^{8} \\
63 & 5^{8} \\
59 \cdot 5\end{array}$ & $\begin{array}{cc}56 & 46 \\
47 & 75 \\
{ }_{5}^{6} \cdot 0^{6}\end{array}$ & $5^{8 \cdot 5}$ \\
\hline Clone mean. & . & $60 \cdot 7$ & 53.7 & $61 \cdot 2$ & $60 \cdot 5$ & $57 \cdot 6$ & \\
\hline
\end{tabular}

Italic : Mean of the 4 plants coming from the same clone with the same ortet environment.

\begin{tabular}{|c|c|c|c|c|}
\hline Source & d.f. & $\begin{array}{c}\text { Mean } \\
\text { square }\end{array}$ & $\begin{array}{c}\text { Expected } \\
\text { mean square }\end{array}$ & $\begin{array}{l}\text { Estimated } \\
\text { component }\end{array}$ \\
\hline Ortet environment & 3 & I $66 \cdot 67^{*}$ & $\sigma_{e}^{2}+20 \sigma_{t}^{2}$ & $\sigma_{t}^{2}=5.65$ \\
\hline Clones & 4 & I $58.50^{*}$ & $\sigma_{e}^{2}+16 \sigma_{c l}^{2}$ & $\sigma_{c l}^{2}=6 \cdot 55$ \\
\hline Interaction & 12 & $66 \cdot 67$ & $\sigma_{e}^{2}+4 \sigma_{i}^{2}$ & $\sigma_{i}^{2}=3.24$ \\
\hline Ramet environment & 60 & 53.72 & $\sigma_{e}^{2}$ & $\sigma_{e}^{2}=53.72$ \\
\hline
\end{tabular}

* Significant at 5 per cent. level.

due to low night temperatures experienced outdoors), and ramets from ortets grown in saturated soil (water) tend to flower earlier than those from ortets grown under repeated water stress (sand). Clone I 34 tends to flower earlier than average no matter what the source of its ramets. The analysis indicates that the majority of variation is associated with the environment of the ramets, much smaller but 
statistically significant amounts of variation are associated with the four ortet environments and the five clones, and a still smaller and statistically non-significant amount of variation is associated with interactions between the clones and ortet environments.

TABLE 2

Variance component estimates

\begin{tabular}{|l|c|c|c|c|}
\hline & $\begin{array}{c}\text { Four-week } \\
\text { height } \\
\text { (mm.) }\end{array}$ & $\begin{array}{c}\text { Days to first } \\
\text { flower }\end{array}$ & $\begin{array}{c}\text { Height to } \\
\text { first floral } \\
\text { node (mm.) }\end{array}$ & $\begin{array}{c}\text { 6-Internode } \\
\text { length } \\
\text { (mm.) }\end{array}$ \\
\hline
\end{tabular}

Experiment I. Grown June-July $\mathcal{N}=45$ Ramets from 3, 7 and I I week old ortets.

\begin{tabular}{|c|c|c|c|c|}
\hline $\begin{array}{l}\text { Age of ortets. } \\
\text { Clones . } \\
\text { Interaction } \\
\text { Ramet environment }\end{array}$ & $\begin{array}{l}233^{\circ * *} \\
341^{* *} \\
121 \\
531\end{array}$ & $\begin{array}{l}8.94^{* *} \\
8.91^{* *} \\
-0.20 \\
12.62\end{array}$ & - & $\begin{array}{r}310^{* *} \\
1683^{* *} \\
-188 \\
941\end{array}$ \\
\hline
\end{tabular}

Experiment 2. Grown Oct.-Dec. $\mathcal{N}=60$ Ramets from 4, 8 and 12 week old ortets.

\begin{tabular}{|c|c|c|c|c|}
\hline $\begin{array}{l}\text { Age of ortets } \\
\text { Clones } \\
\text { Interaction } \\
\text { Ramet environment }\end{array}$ & $\begin{array}{l}14^{8 * *} \\
11 \\
213^{* *} \\
397\end{array}$ & $\begin{array}{r}0 \cdot 14 \\
3 \cdot 4^{8} \\
9 \cdot 02 \\
32 \cdot 18\end{array}$ & $\begin{array}{l}\text { I } 92 \\
\text { I } 573^{* *} \\
\text { I } 134^{*} \\
3004\end{array}$ & $\begin{array}{l}-15 \\
1826^{* *} \\
200^{*} \\
539\end{array}$ \\
\hline
\end{tabular}

Experiment 3. Grown June-July $\mathcal{N}=60$

Ramets from axillary branches, soil runners and water runners.

\begin{tabular}{|l|r|r|r|r|}
\hline Type of rooted node & 3 & $-2 \cdot 07$ & 318 & -33 \\
Clones . . & 126 & $14^{\cdot 09^{* *}}$ & 593 & $1563^{* *}$ \\
Interaction . & 221 & $31 \cdot 66^{* *}$ & $54^{8}$ & -103 \\
Ramet environment & 1726 & $4^{1 \cdot 45}$ & $5^{212}$ & 1390 \\
\hline
\end{tabular}

Experiment 4. Grown Oct.-Dec. $\mathcal{N}=80$

Ramets from ortets grown inside in water or sand, or outside in water or sand.

\begin{tabular}{l|l|c|c|c|}
\hline Ortet environment. & $79^{*}$ & $5 \cdot 65^{*}$ & 131 & 19 \\
Clones . & 34 & $6 \cdot 55^{*}$ & $3543^{* *}$ & $27^{* *}$ \\
Interaction . & $297^{* *}$ & $3 \cdot 24$ & -56 & 101 \\
Ramet environment & 745 & $53.7^{*}$ & 4640 & 1291 \\
\hline
\end{tabular}

- Significant at 5 per cent. level.

** Significant at I per cent. level.

There are 16 combinations of characters and experiments. Table 2 summarises the variance component estimates from 15 of these, the I 6 th being unanalysable due to an error during data taking. In table 3 , the sources of variation are presented as a percent of the total variation for each experiment.

The earliest of the characters, four-week height, is strongly influenced by differences in the source of the nodes initiating the ramets, 
and less influenced by differences in the genetic make-up of the five clones, except possibly as the clones interacted with the ortet treatments.

Flowering occurs from six to twelve weeks after cloning, and elongation below the first flowering node is completed about a week later. These two characters are less influenced by early physiological and morphological differences, as is shown by the decreasing relative amounts of the treatments and interaction components, and are more

TABLE 3

Percent of variation

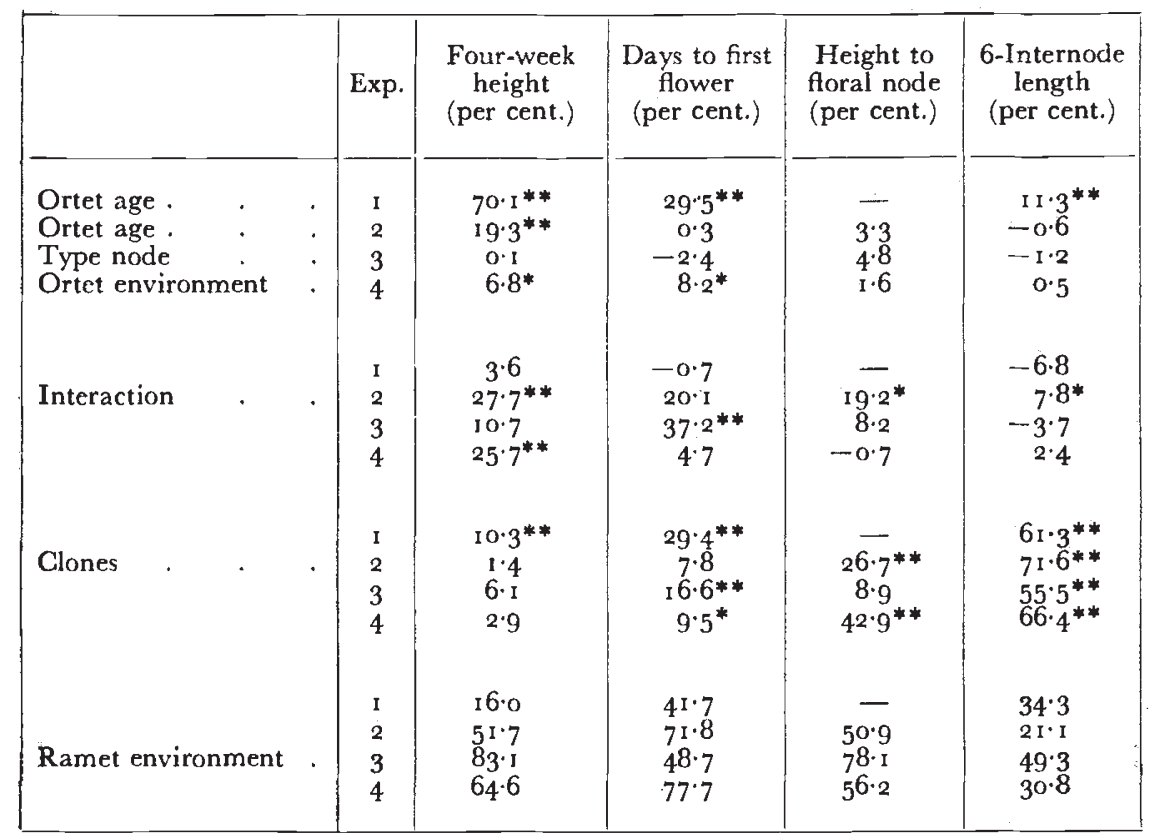

* Significant at 5 per cent. level.

** Significant at I per cent. level.

strongly controlled by the genotypes of the clones, as shown by the increasing importance of the clonal components.

Finally, six-internode length, which completes development from nine to sixteen weeks after cloning, is still less influenced by the early physiological and morphological condition of the ramets, and most strongly influenced by the genotypes of the five clones. The age of ortets effect in the first experiment, and the ortet age $\times$ clones interaction in the second, are still statistically significant with respect to sixinternode length, but account for only i I per cent. and 8 per cent. of the total variation of that character in their respective experiments.

It should be mentioned that the data for four-week height and six-internode length were distinctly skew. Transformation to a logarithmic scale distributed the data normally. Analyses of the 
transformed data shifted the relative contributions to variation by a few per cent., and changed a few significance levels. In no case, however, was the order of importance or order of magnitude of any component changed. Since the relative behaviour of the components, not their absolute values or significance, is of primary interest in this study, the data were all left in their arithmetic form in this presentation.

\section{DISCUSSION AND CONCLUSIONS}

Where appreciable "c" effects associated with cloning exist, bias and overestimates of broad-sense heritability and the total genetic and non-additive genetic components of variance will result if some forms of clonal analysis are used. In addition, such effects will also reduce the efficiency of selection based on the performance of clones. The clonal component of variance for characters which are scored soon after cloning, such as four-week height, is likely to contain a high level of " $c$ " effects variance. However, characters which develop later probably contain a lower or vanishing level of "c" effects in the clonal component. Internal physiological balances and systems within each ramet will have developed in response to the unique micro-environments of the different ramets, largely replacing the common physiological and morphological condition of the vegetative parts at the time of cloning. This trend toward autonomy is clear in Donald's experiment with cattle twins, and in the four Mimulus experiments described above.

The level of " $c$ " effects variation associated with cloning may be estimated by using a nested design. Thus, by sampling the clones in a cloned population, and using more than one individual per clone as an ortet for the estimating experiment, it would be possible to estimate variation between ramets of a single ortet (environment), between ramets of different ortets within a clone (" c" effects), and between clones (genetic). By utilising unusually diverse conditions within clones, such as the four experiments described above, it is possible to recognise the presence of " $c$ " effects variation with small experiments. Such experiments do not, however, estimate the level of " $c$ " effects in a normally-cloned population. If " $c$ " effects are small or absent in such diverse-condition experiments, it seems safe to conclude that they are negligible in a normally-cloned population. However, if they are a major component of variation in diverse-condition experiments, then there is a possibility of bias in clonal estimation of population parameters, or of overestimating the predicted gain for clonal selection.

Where appreciable bias due to cloning "c" effects seems probable, it may be reduced statistically or experimentally. The statistical approach relies on the procedure of growing a random population of seedlings and clones together. The clones are used to estimate environmental variance, and the seedlings are used for total variance. (The seedlings and replicated clones may be grown over a range of 

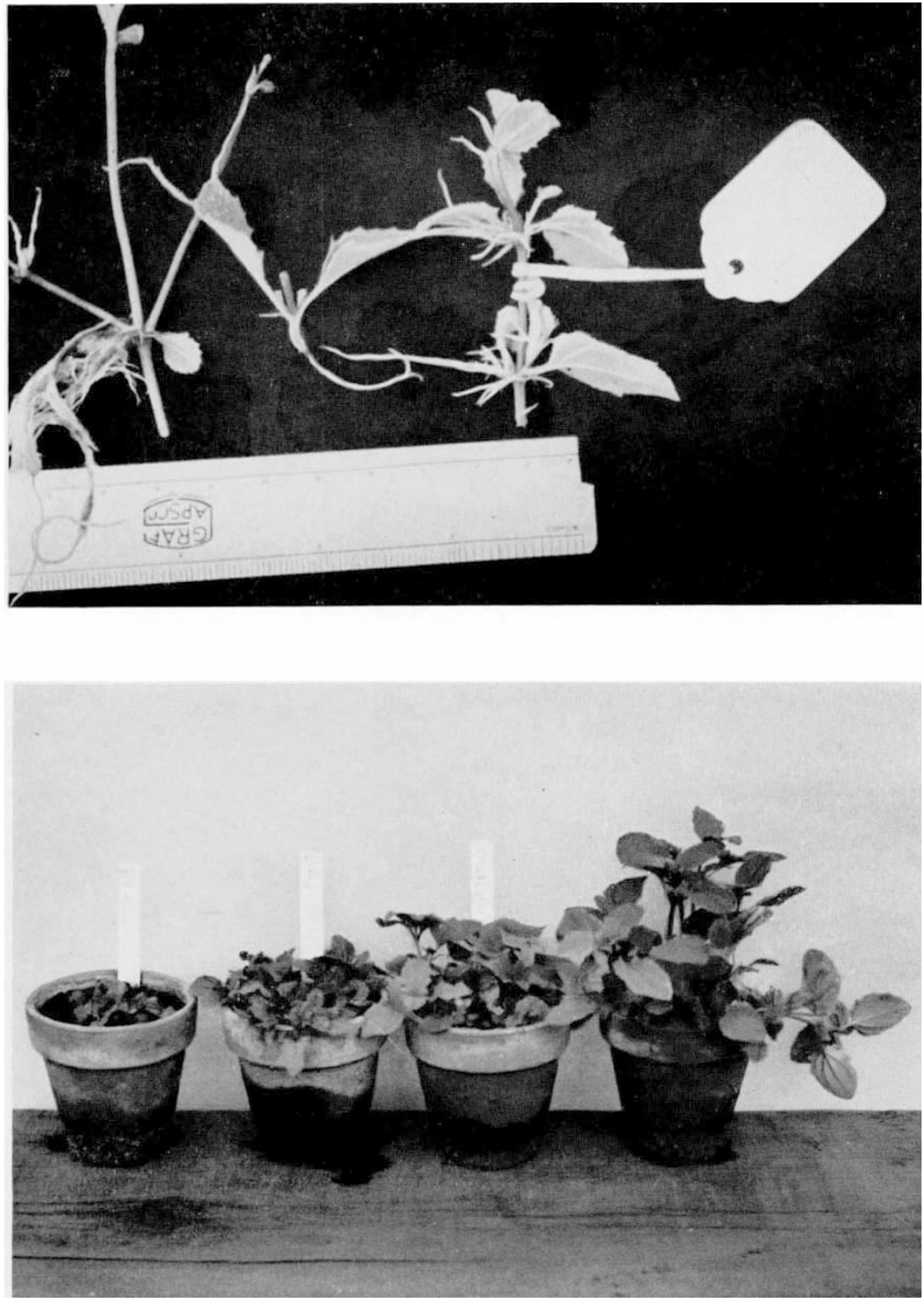

Top.--Nodes from the same ortet of clone 134 . The cuttings on the left and in the centre come from runners which develop under water, and on the surface of the soil, respectively. They werc removed from the plant just prior to taking the picture. The cutting on the right was an axillary branch, and was removed a week earlier and rooted in moist sand. The small (two roots) node at the far left of the picture, the single node from the soil runncr, and the second node above the tag on the axillary branch would be used to produce ramets in an experiment.

Bottom.-This picture was taken on I 5 th October, just before four nodes were taken from each pot. Five ramets of clone 222 have developed in each of these pots for one month. The pots were kept in the following four cnvironments : (left to right) outside in sand, outside in water, inside in sand and insidc in water. 
environments, so that that level of genotype-environment interaction would be included in the within-clone variance.) The difference between the two estimates would estimate the total genetic variance, and could be used to estimate broad-sense heritability. The bias is removed, since cloning "c" effects would not appear in seedling total variance, and would be in the "between clones" component of the clonal analysis, which is not used to estimate the environmental variance. Variations of this scheme have been used in several studies (Kalton, Smit and Leffel, I952; McDonald, Kalton and Weiss, I 952; Comstock, Kelleher and Morrow, I958; Toda, 1958). Poor cloning technique, however, can cause an increase in within-clone variance, since a character susceptible to covariance within clones due to similarity of vegetative propagules is just as susceptible to variance within clones due to dissimilarity of the propagules.

An experimental reduction of cloning " c " effects may be achieved by a two-stage cloning. If, say, four ramets per clone are desired either for estimation of variance components or for clonal selection, each plant is first cloned four times and the ramets assigned random positions in the non-uniform experiment environment. After they have had time to respond to their random and unique micro-environments, each plant in this first-stage group of ramets is recloned once to form a second-stage, or experiment population. These second-stage ramets will have strong non-genetic correlations with the plants from which they were just cloned, but not with each other. If the first-stage ramets have been allowed to sufficiently respond to their micro-environments, the "c" effects affecting the second-stage ramets should be a good sample of the response of their genotypes to the population of experiment micro-environments.

\section{SUMMARY}

The relative amounts of variation associated with cloning are measured for a sequence of four related characters in Mimulus guttatus. A trend from a high level of "c" effects in the characters expressed earlier to virtual absence of " $c$ " effects in the characters expressed later is evident in each of the four experiments. It is suggested that the relative importance of "c" effects with respect to different characters may be evaluated by using propagules with unusually diverse morphological or physiological conditions within a genotype. This information will aid in evaluating the probable importance of " $c$ " effects associated with cloning in a normally-cloned population, although the method does not directly estimate the level of " $c$ " effects in such a population. Two possible methods of reducing bias due to "c " effects are discussed.

Acknowledgments.-This research was carried out during the senior author's tenure of two National Science Foundation Fellowships, and was supported in part by a grant-in-aid from the U.S. Forest Service. We wish to thank Dr E. R. Dempster and Mr P. Dawson, of the University of California, and Dr H. F. Robinson and Dr T. Kelleher, of North Carolina State College, who have kindly read and criticised the manuscript. 


\section{REFERENCES}

BUtron, G. W. AND E. H. DEvane. I953. Estimating heritability in tall fesque

(Festuca arundinacea) from replicated clonal material. Agron. Jour., 45, 478-481. COMSTOCK, R. E., T. KELLEHER, AND E. B. MORROW. I958. Genetic variation in an asexual species, the garden strawberry. Genetics, 43, 634-646.

COOPER, J. P. I959. Selection and population structure in Lolium II. Genetic control of date of ear emergence. Heredity, 13, 445-459.

DONALD, H. P. 1958. Evidence from twins on variation in growth and production of cattle. Proc. X Int. Cong. Genetics, I, 225-235.

KALTON, R. R., SMIT, A. G., AND LEFFEL, R. G. I952. Parent-inbred progeny relationships of selected orchardgrass clones. Agron. Jour., 44, 48 I-486.

KELLER, K. R., AND LIKENS, s. T. I955. Estimates of heritability in hops, Humulus lupulus. Agron. Jour., 47, 518-52 I.

LIBBy, w. J. I961. The use of clones in selection and estimation of variance components and heritability in Mimulus guttatus. Ph.D. Dissertation, University of Calfornia, Berkeley.

LIBBy, w. J. 1962. Estimation of variance components of internode length in a cloned population of Mimulus guttatus. Genetics, 47, 769-777.

MCDONALD, E. D., KALTON, R. R., AND WEISs, M. G. I952. Interrelationships and relative variability among $\mathrm{S}_{1}$ and open-pollinated progenies of selected bromegrass clones. Agron. Four., 44, 20-25.

MORROW, E. B., COMSTOCK, R. E., AND KELLEHER, T. I958. Genetic variances in strawberries. Proc. Am. Soc. Hort. Sci., 72, I $70-185$.

SCHEFFE, H. I 959. The analysis of variance. John Wiley and Sons, New York. $477 \mathrm{pp}$. TODA, R. 1958. Variation and heritability of some quantitative characters in Cryptomeria. Silve Genetica, 7, 87-93. 